\title{
Annealing Heat Treatment of ZnO Nanoparticles Grown on Porous Si Substrate Using Spin-Coating Method
}

\author{
K. A. Eswar, ${ }^{1,2}$ J. Rouhi, ${ }^{1}$ H. F. Husairi, ${ }^{1,2}$ M. Rusop, ${ }^{1,3}$ and S. Abdullah ${ }^{1,2}$ \\ ${ }^{1}$ NANO-SciTech Centre (NST), Institute of Science, Universiti Teknologi Mara (UiTM), 40450 Shah Alam, \\ Selangor, Malaysia \\ ${ }^{2}$ Faculty of Applied Sciences, Universiti Teknologi Mara (UiTM), 40450 Shah Alam, Selangor, Malaysia \\ ${ }^{3}$ NANO-Electric Centre (NET), Faculty of Electrical Engineering, Universiti Teknologi Mara (UiTM), \\ 40450 Shah Alam, Selangor, Malaysia
}

Correspondence should be addressed to K. A. Eswar; kevinalvin86@gmail.com

Received 20 May 2013; Revised 20 November 2013; Accepted 20 November 2013; Published 4 February 2014

Academic Editor: Jainagesh Sekhar

Copyright (c) $2014 \mathrm{~K}$. A. Eswar et al. This is an open access article distributed under the Creative Commons Attribution License, which permits unrestricted use, distribution, and reproduction in any medium, provided the original work is properly cited.

$\mathrm{ZnO}$ nanoparticles were successfully deposited on porous silicon (PSi) substrate using spin-coating method. In order to prepare PSi, electrochemical etching was employed to modify the Si surface. Zinc acetate dihydrate was used as a starting material in ZnO solgel solution preparation. The postannealing treatments were investigated on morphologies and photoluminescence (PL) properties of the $\mathrm{ZnO}$ thin films. Field emission scanning electron microscopy (FESEM) results indicate that the thin films composed by $\mathrm{ZnO}$ nanoparticles were distributed uniformly on PSi. The average sizes of $\mathrm{ZnO}$ nanoparticle increase with increasing annealing temperature. Atomic force microscopic (AFM) analysis reveals that $\mathrm{ZnO}$ thin films annealed at $500^{\circ} \mathrm{C}$ had the smoothest surface. $\mathrm{PL}$ spectra show two peaks that completely correspond to nanostructured $\mathrm{ZnO}$ and PSi. These findings indicate that the $\mathrm{ZnO}$ nanostructures grown on PSi are promising for application as light emitting devices.

\section{Introduction}

In the past decade, developing high-quality semiconductor nanostructures has attracted increasing attention due to promising applications in electronic and optoelectronic devices arising from their physical properties. $\mathrm{ZnO}$ is a wide band gap semiconductor with excellent chemical stability and high exciton binding energy [1]. These properties make it widely used in optoelectronic devices such as solar cells, gas sensor, UV sensor, LED applications, and so on [2-6]. In order to synthesis $\mathrm{ZnO}$, various methods were applied such as laser deposition [4], RF magnetron sputtering [3, 5], mistatomization [7], and sol-gel deposition [2, 6, 8, 9].

High quality $\mathrm{ZnO}$ nanostructures were obtained by very expensive and complicated equipment [10]. However, expensive and complicated equipments for $\mathrm{ZnO}$ synthesization are not applicable in large scale productions. In this work, $\mathrm{ZnO}$ thin film was deposited by sol-gel spin coating. This simple method is using less expensive equipment and easy to handle compared to other technique. So, this low-cost technique becomes more promising in bulk productions.

Other than that, substrate selection is very important to $\mathrm{ZnO}$ thin film properties. Physical, optical, and electrical properties of $\mathrm{ZnO}$ will be different using different substrates. Suresh Kumar et al. have studied the deposition of $\mathrm{ZnO}$ nanostructure on indium-tin oxide (ITO), glass and polyethylene terephthalate polymer (PET) substrates [11]. They found that different substrates will produce different type of $\mathrm{ZnO}$ nanostructures. Besides, substrate selections are also based on its device application. Mamat et al. have fabricated UV photoconductive sensors on glass substrate [12] and Gao et al. have deposited $\mathrm{ZnO}$ films on silicon wafer in order to study the optical properties for solar cells applications. Besides, Yang et al. suggested that white light emitting diode can be produced by depositing ZnO films on PSi substrate [5].

In this work, PSi substrate was prepared by modifying the silicon wafer surface using electrochemical anodization method. Kim et al. suggested that modification of silicon 


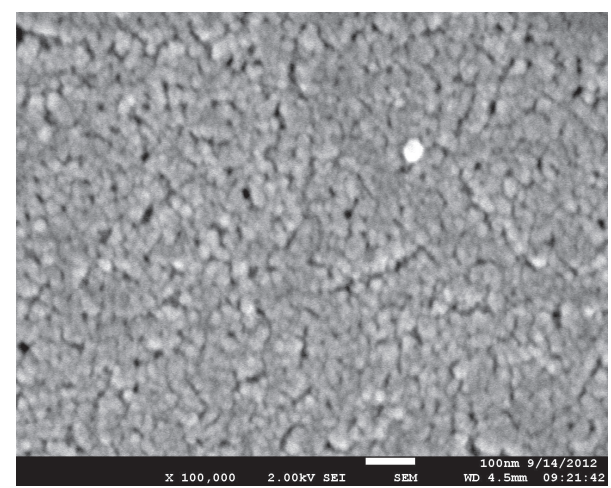

(a)

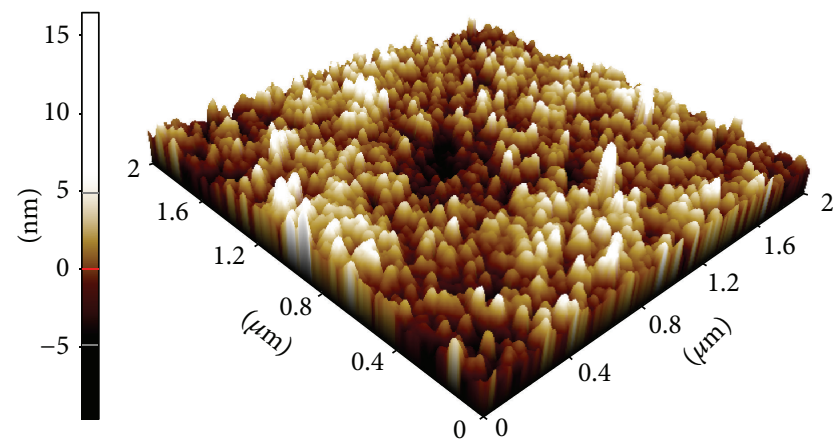

(b)

FIGURE 1: (a) FESEM image and (b) three-dimensional AFM image of PSi.

surface can reduce the effect of large lattice mismatch between single crystalline silicon wafer and $\mathrm{ZnO}[13,14]$.

Investigation on various parameters such as heat treatment, molarity of precursor and stabilizer, and aging time was being conducted. The results show that the growth of $\mathrm{ZnO}$ thin films is influenced by these parameters, including its optical and electrical properties [15-18]. In order to study the postheat treatment, annealing temperatures were varied in a range of $300^{\circ} \mathrm{C}$ to $700^{\circ} \mathrm{C}$ while other parameters are maintained.

\section{Experimental}

Zinc acetate dehydrates were used as a starting material, while diethanolamine and isopropyl are used as a stabilizer and solvent, respectively. P-type silicon wafer was used in PSi preparation. Firstly, silicon wafer was cleaned by acetone, followed by methanol and diluted hydrofluoric $40 \%$ acid in ultrasonic bath. Then, the silicon was dried by nitrogen gas before being etched by electrochemical etching. Hydrofluoric acid $48 \%$ was mixed with absolute ethanol (HF48\%: absolute ethanol = ratio of $1: 1$ ) was used as an electrolyte. Current densities and time were maintained at $20 \mathrm{~mA} / \mathrm{cm}^{2}$ and 20 minutes during etching process. $\mathrm{ZnO}$ precursor was prepared by dissolving $0.15 \mathrm{M}$ of znic acetate into isopropyl and stirred. Then, diethanolamine was added slowly into the solution and heated at $60^{\circ} \mathrm{C}$ for an hour to yield a clear and homogenous solution. After that, the solution was continued stirred and aged at room temperature for 24 hours. The ratio of zinc acetate to diethanolamine was fixed at 1.0.

Spin coating method was used to deposit $\mathrm{ZnO}$ thin films on PSi surface. Rotation per minute was maintained at 3000 within 60 seconds. Then, 10 drops of $\mathrm{ZnO}$ precursor were dropped on surface of rotated PSi. After that, $\mathrm{ZnO}$ thin film was dried at $150^{\circ} \mathrm{C}$ for 10 minutes to remove any volatile components. These processes were repeated 10 times to increase the thicknesses of $\mathrm{ZnO}$ thin film. Finally, $\mathrm{ZnO}$ thin films were annealed in various temperatures in a range of $300^{\circ} \mathrm{C}$ to $700^{\circ} \mathrm{C}$ for an hour.

$\mathrm{ZnO}$ thin films were studied by FESEM, model JEOL JSM-J600F. AFM (model XE-100 of Park Systems) was employed to study the roughness of $\mathrm{ZnO}$ thin films. PL spectra were studied at room temperature by HORIBA Jobin Yvon's LabRAM $800 \mathrm{HR}$ with $325 \mathrm{~nm} \mathrm{He-Cd}$ laser as a source.

\section{Result and Discussions}

The p-type silicon wafer surface was successfully modified to porous after being etched at current densities $20 \mathrm{~mA} / \mathrm{cm}^{2}$ for 20 minutes. Figure 1 shows the FESEM and AFM images of PSi. As seen in Figure 1, irregular pores with sizes in range of $\sim 11.9 \mathrm{~nm}$ to $\sim 30.6 \mathrm{~nm}$ were distributed over the PSi surface. The surface roughness average of porous is $1.953 \mathrm{~nm}$ while silicon wafer is $0.314 \mathrm{~nm}$. This shows that PSi was successfully prepared in this work. The interreaction between silicon wafer and hydrofluoric acid is suggested in (1) [19]:

$$
\mathrm{Si}+6 \mathrm{~F}^{-}+2 \mathrm{H}^{+} \longrightarrow \mathrm{SiF}_{6}^{2-}+\mathrm{H}_{2}
$$

$\mathrm{ZnO}$ thin film deposited on PSi was shown in Figure 2. The left hand side is FESEM images while three-dimensional AFM image is on the right hand side. Based on FESEM images, the thin film are composed by $\mathrm{ZnO}$ nanoparticles. Besides, the pores can also be seen on the surface.

The pores are clearly seen when the thin films were annealed at $500^{\circ} \mathrm{C}$. The averages of particle size depend on postannealing temperatures. Figure 3 shows the average particle sizes of $\mathrm{ZnO}$ nanoparticle in different annealing temperatures. The particle size of $24.7 \mathrm{~nm}$ increases $25.64286 \mathrm{~nm}$ when annealing temperature increased from $300^{\circ} \mathrm{C}$ to $400^{\circ} \mathrm{C}$. This can be explained by thermal expansion where the kinetic energy of atom increases due to increases of annealing temperatures. However, the average particles sizes were decreased to $24.37143 \mathrm{~nm}$ at annealing temperature of $500^{\circ} \mathrm{C}$ and $21.32857 \mathrm{~nm}$ at $600^{\circ} \mathrm{C}$. It is attributed by the atom which got sufficient thermal energy and move to any space within the particle or crystalline rearrangement. So, the size of particle decreased due to full filled space within the crystalline. It is believed that the crystalline quality also increased because the atom will move to the favorable position [20]. The atom will move to the adjacent particle at $700^{\circ} \mathrm{C}$. So, it will merge into adjacent particle and form larger particle. 


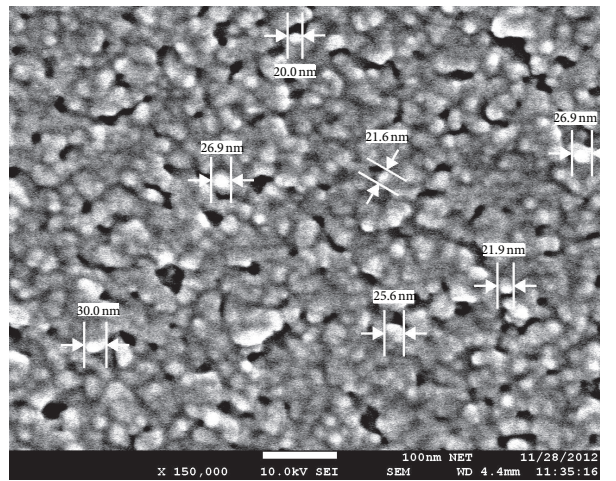

(a)

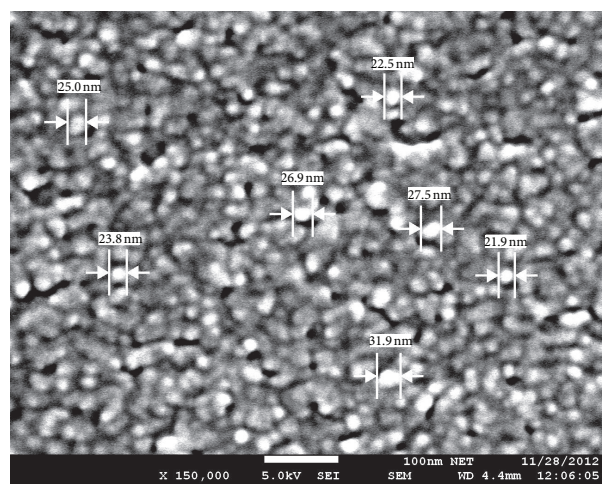

(b)

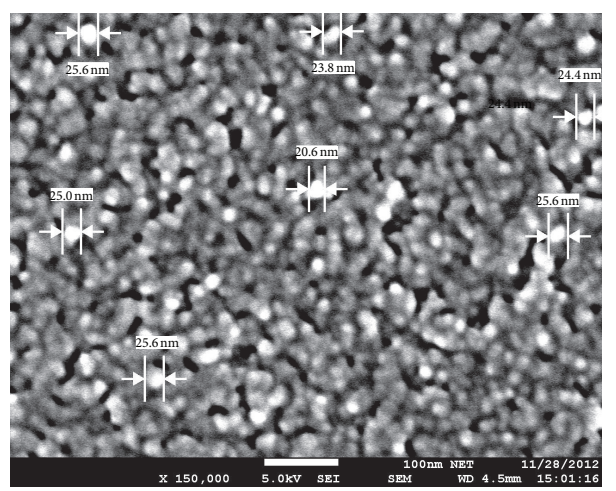

(c)

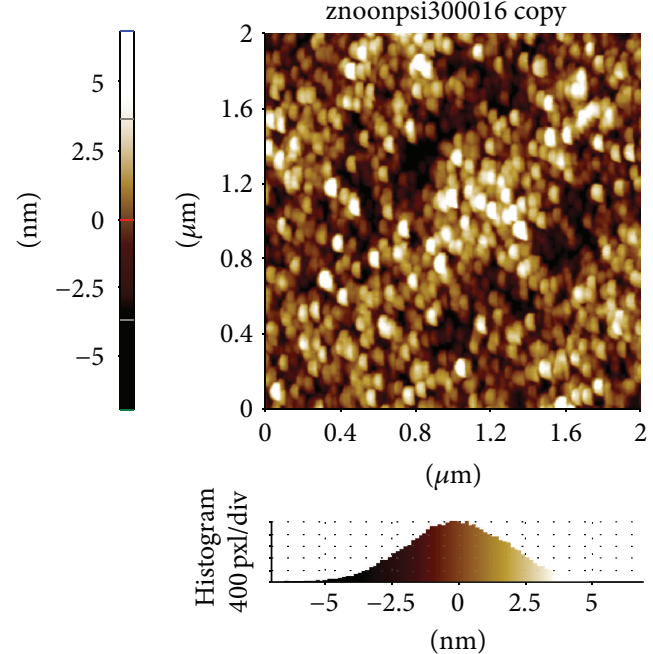

(i)
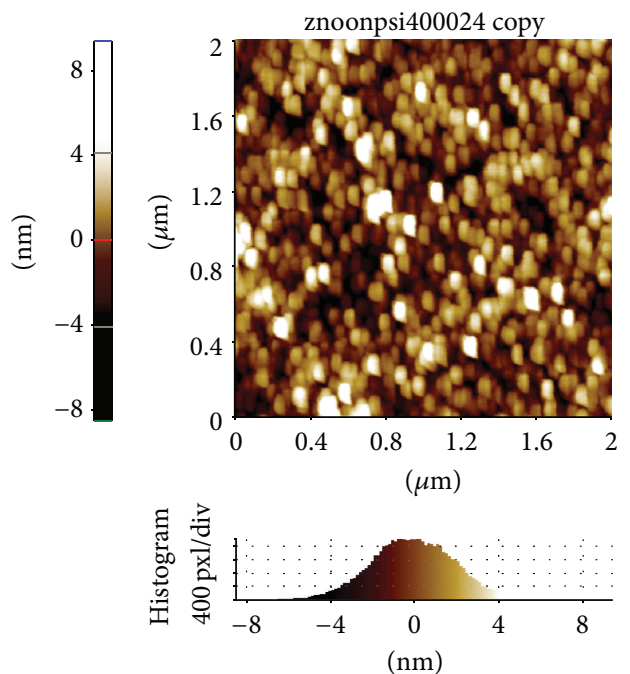

(ii)

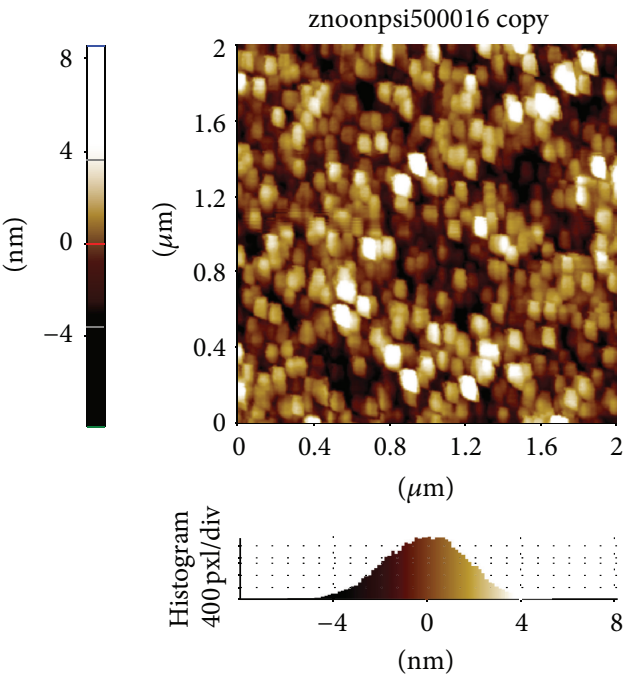

(iii)

Figure 2: Continued. 


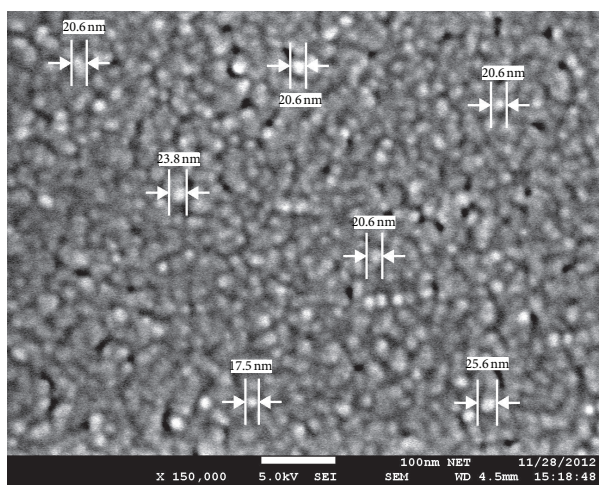

(d)

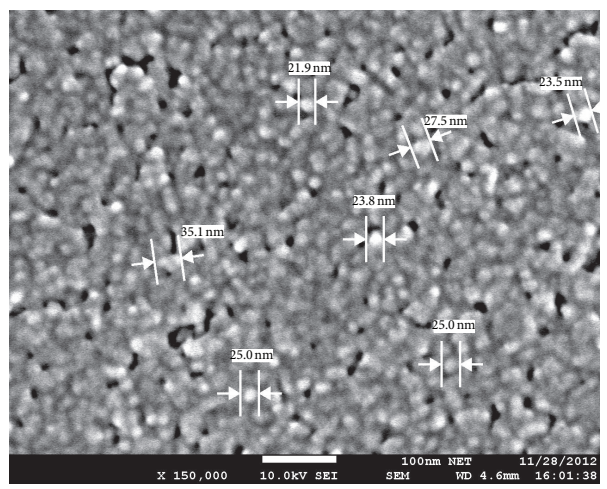

(e)

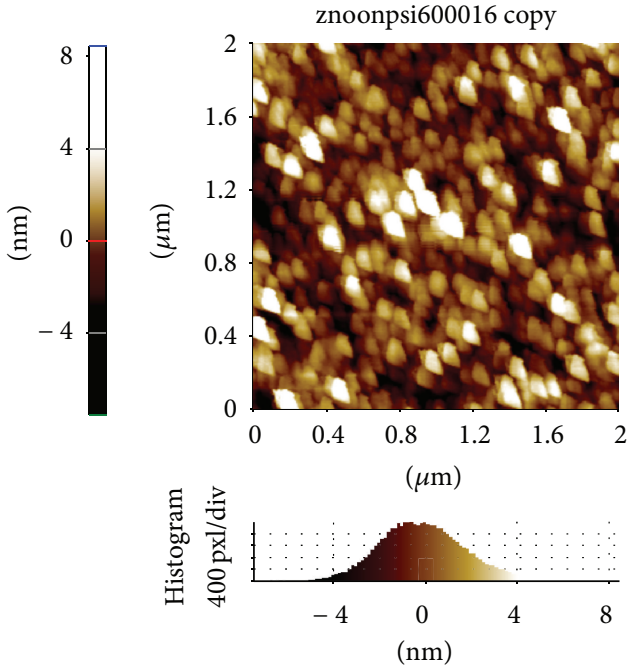

(iv)

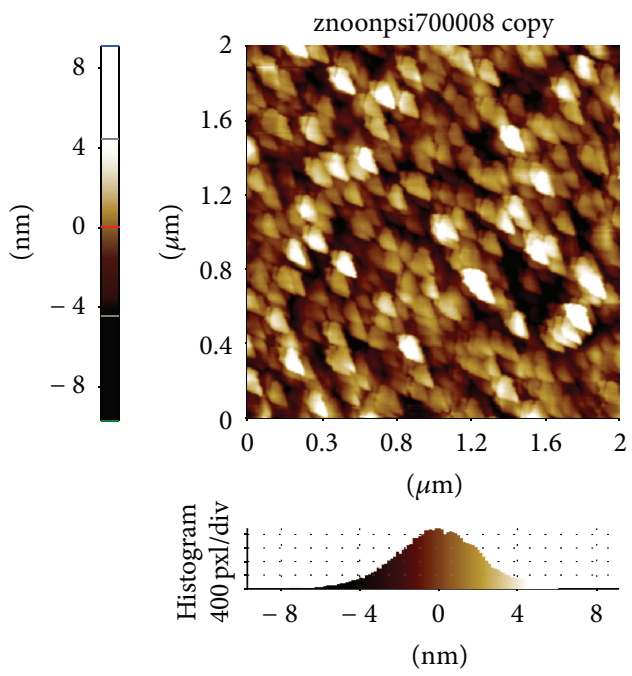

(v)

FIGURE 2: FESEM and AFM images of ZnO thin films on PSi annealed at (a) and (i) $300^{\circ} \mathrm{C}$, (b) and (ii) $400^{\circ} \mathrm{C}$, (c) and (iii) $500^{\circ} \mathrm{C}$, (d) and (iv) $600^{\circ} \mathrm{C}$, and (e) and (v) $700^{\circ} \mathrm{C}$.

The average surface roughness of $\mathrm{ZnO}$ thin film surface is $1.501 \mathrm{~nm}$ at annealing temperature of $300^{\circ} \mathrm{C}$ and increases to $1.643 \mathrm{~nm}$ at $400^{\circ} \mathrm{C}$. However, the average surface roughness decreases to $1.455 \mathrm{~nm}$ at $500^{\circ} \mathrm{C}$. Then it becomes rougher after increasing the annealing temperatures. The average surface roughness of thin film is increased at $400^{\circ} \mathrm{C}$ due to increases of particle size.

After being annealed at $500^{\circ} \mathrm{C}$, the crystalline quality increases due to that atom arrangements that are in favorable position make the average surface roughness decreases. However, the average surface roughness increases after that due to increases of particle size.

Figure 4 shows the PL spectra of $\mathrm{ZnO}$ thin film composed nanoparticles on porous in a range of $350 \mathrm{~nm}$ to $900 \mathrm{~nm}$. There are three main peaks within the range of $400 \mathrm{~nm}$ to $420 \mathrm{~nm}, 550 \mathrm{~nm}$ to $600 \mathrm{~nm}$, and $625 \mathrm{~nm}$ to $725 \mathrm{~nm}$ belongs to $\mathrm{ZnO}$, defects of $\mathrm{ZnO}$ thin film and PSi, respectively [21, 22].
The peak within the range of $400 \mathrm{~nm}$ to $420 \mathrm{~nm}$ is free-exciton recombination of $\mathrm{ZnO}$ thin film [20].

The deep-level emissions ( $550 \mathrm{~nm}$ to $600 \mathrm{~nm}$ ) from the $\mathrm{ZnO}$ nanostructures were possibly caused by intrinsic and structural defects in $\mathrm{ZnO}$ that form deep energy levels in the $\mathrm{ZnO}$ band gap. These defects represent oxygen and zinc interstitials, as well as oxygen and zinc vacancies [21]. Kim et al. reported that the peak within the red region is generated by radiative recombination of excitons on the surface of PSi [20]. The peaks which contributed free-exciton recombination are less affected by postannealing temperature in this work. However, the intensities of the peak in the range $550 \mathrm{~nm}$ to $600 \mathrm{~nm}$ gradually decrease due to increases of postannealing temperatures. This is attributed by the crystalline of the $\mathrm{ZnO}$ thin film. By increasing the temperature, the atom moves to a favorable position. So, the defects such oxygen vacancies and zinc interstitial will reduce. 


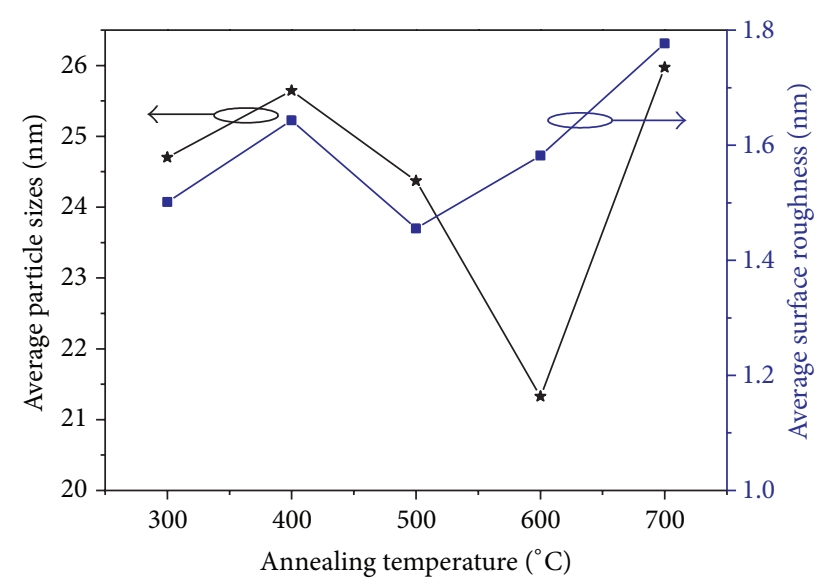

FIgURE 3: Average particle size of $\mathrm{ZnO}$ nanoparticles and surface roughness in different annealing temperatures.

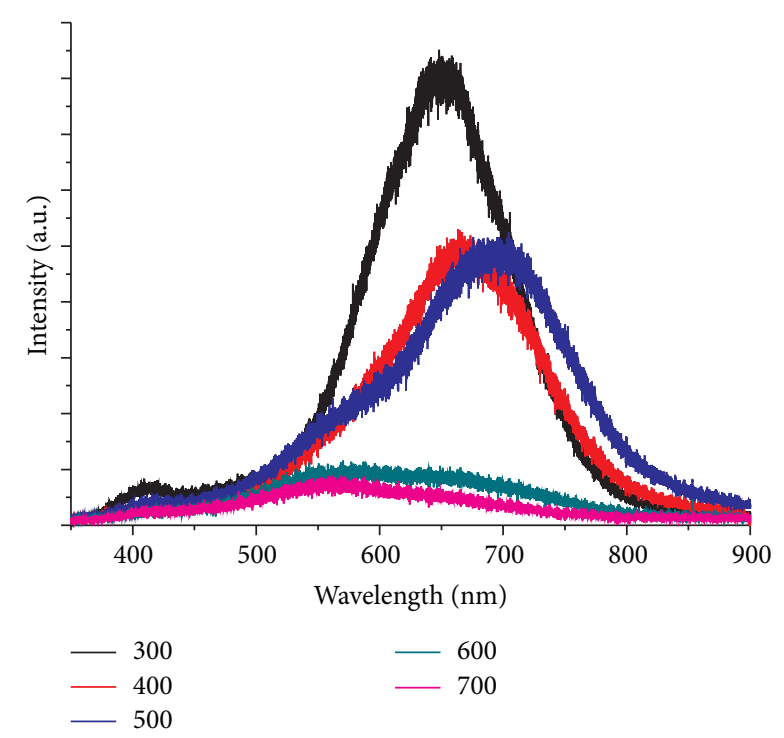

FIGURE 4: PL spectra of $\mathrm{ZnO}$ thin film composed nanoparticles on PSi in range of $350 \mathrm{~nm}$ to $900 \mathrm{~nm}$.

The peaks in range of $625 \mathrm{~nm}$ to $725 \mathrm{~nm}$ are highly affected by postannealing temperatures. The peak at postannealing of $300^{\circ} \mathrm{C}$ was attributed by the combination of defects of $\mathrm{ZnO}$ and radiative recombination of excitons on the surface of PSi. The increases of crystal-line quality of $\mathrm{ZnO}$ reduced the intensities of the peaks and red-shifted attributed by only PSi surfaces. The intensities tend to diminish after being annealed at $600^{\circ} \mathrm{C}$ and $700^{\circ} \mathrm{C}$. We suggested the pores on silicon surfaces were full-filled by $\mathrm{ZnO}$ nanoparticles.

\section{Conclusions}

In summary, the $\mathrm{ZnO}$ thin film was successfully deposited on PSi. FESEM and AFM images revealed that the thin films are composed by $\mathrm{ZnO}$ nanoparticles. The average $\mathrm{ZnO}$ particles sizes depend on postannealing temperatures. Besides, the
PL spectra are also affected by the annealing temperature attributed by the physical changes of $\mathrm{ZnO}$ nanoparticles.

\section{Conflict of Interests}

The authors declare that there is no conflict of interests regarding the publication of this paper.

\section{Acknowledgments}

The authors would like to thank the Ministry of High Education of Malaysia and Universiti Teknologi MARA (UiTM) for their financial and instrumental support. The authors would also like to thank the Faculty of Electrical Engineering (Mr. Danial and Mr. Sharil) for the use of their FESEM. Furthermore, the authors thank Mr. Salifairus Jaafar (UiTM Science Officer), Mrs. Nurul Wahida (UiTM Assistant Science Officer), and Mr. Mohd Azlan Jaafar (UiTM technician) for their kind support of this research.

\section{References}

[1] M. Alimanesh, J. Rouhi, N. Zainal, S. Kakooei, and Z. Hassan, "Growth of vertically aligned $\mathrm{ZnO}$ nanorods arrays by hydrothermal method," Advanced Materials Research, vol. 795, pp. 616-619, 2013.

[2] F. Tong, K. Kim, Y. Wang et al., "Growth of $\mathrm{ZnO}$ nanorod arrays on flexible substrates: effect of precursor solution concentration," ISRN Nanomaterials, vol. 2012, Article ID 651468, 7 pages, 2012.

[3] Y. Kumar, J. E. Garcia, F. Singh et al., "Influence of mesoporous substrate morphology on the structural, optical and electrical properties of RF sputtered $\mathrm{ZnO}$ layer deposited over porous silicon nanostructure," Applied Surface Science, vol. 258, no. 7, pp. 2283-2288, 2012.

[4] K. Gao, Q. Li, Z. Hu et al., "Correlation between structure and photoluminescence of c-axis oriented nanocrystalline $\mathrm{ZnO}$ films and evolution of photo-generated excitons," Solar Energy Materials and Solar Cells, vol. 96, no. 1, pp. 117-123, 2012.

[5] F. Yang, S. Ma, X. Zhang et al., "Blue-green and red luminescence from $\mathrm{ZnO}$ /porous silicon and $\mathrm{ZnO}: \mathrm{Cu} /$ porous silicon nanocomposite films," Superlattices and Microstructures, vol. 52, no. 2, pp. 210-220, 2012.

[6] M. H. Mamat, N. I. Ishak, Z. Khusaimi et al., "Thicknessdependent characteristics of aluminium-doped zinc oxide nanorod-array-based, ultraviolet photoconductive sensors," Japanese Journal of Applied Physics, vol. 51, Article ID 06FF03, 2012.

[7] Z. Khusaimi, M. H. Mamat, N. Abdullah, and M. Rusop, " $\mathrm{ZnO}$ nanoparticles on $\mathrm{Si}, \mathrm{Si} / \mathrm{Au}$, and $\mathrm{Si} / \mathrm{Au} / \mathrm{ZnO}$ substrates by mistatomisation," Journal of Nanomaterials, vol. 2012, Article ID 872856, 8 pages, 2012.

[8] M. Hafiz Mamat, Z. Khusaimi, and M. Rusop Mahmood, "Optical properties of nanostructured zinc oxides deposited on silicon substrates," Defect and Diffusion Forum, vol. 312-315, pp. 1132-1136, 2011.

[9] K. A. Eswar, A. Ab Aziz, M. Rusop Mahmood, and S. Abdullah, "Surface morphology of seeded nanostructured $\mathrm{ZnO}$ on silicon by Sol-Gel technique," Advanced Materials Research, vol. 667, pp. 265-271, 2013. 
[10] J. Rouhi, S. Mahmud, N. Naderi, C. R. Ooi, and M. R. Mahmood, "Physical properties of fish gelatin-based bio-nanocomposite films incorporated with $\mathrm{ZnO}$ nanorods," Nanoscale Research Letters, vol. 8, no. 1, pp. 1-6, 2013.

[11] P. Suresh Kumar, J. Sundaramurthy, D. Mangalaraj, D. Nataraj, D. Rajarathnam, and M. P. Srinivasan, "Enhanced superhydrophobic and switching behavior of $\mathrm{ZnO}$ nanostructured surfaces prepared by simple solution-immersion successive ionic layer adsorption and reaction process," Journal of Colloid and Interface Science, vol. 363, no. 1, pp. 51-58, 2011.

[12] M. H. Mamat, Z. Khusaimi, M. M. Zahidi, and M. R. Mahmood, "Performance of an ultraviolet photoconductive sensor using well-aligned aluminium-doped zinc-oxide nanorod arrays annealed in an air and oxygen environment," Japanese Journal of Applied Physics, vol. 50, no. 6, Article ID 06GF05, 2011.

[13] M. S. Kim, G. Nam, J. S. Son, and J. Y. Leem, "Photoluminescence studies of $\mathrm{ZnO}$ thin films on porous silicon grown by plasma-assisted molecular beam epitaxy," Current Applied Physics, vol. 12, supplement 4, pp. S94-S98, 2012.

[14] M. Balucani, P. Nenzi, E. Chubenko, A. Klyshko, and V. Bondarenko, "Electrochemical and hydrothermal deposition of $\mathrm{ZnO}$ on silicon: from continuous films to nanocrystals," Journal of Nanoparticle Research, vol. 13, no. 11, pp. 5985-5997, 2011.

[15] M. G. Varnamkhasti, H. R. Fallah, and M. Zadsar, "Effect of heat treatment on characteristics of nanocrystalline $\mathrm{ZnO}$ films by electron beam evaporation," Vacuum, vol. 86, no. 7, pp. 871875, 2012.

[16] A. A. Azlinda, Z. Khusaimi, F. S. Husairi, N. I. Nasruddin, S. Abdullah, and M. Rusop, "Annealing effect on the surface morphology and photoluminescence properties of $\mathrm{ZnO}$ hexagonal rods by immersion method," Advanced Materials Research, vol. 576, pp. 353-356, 2012.

[17] Z. Khusaimi, M. Hafiz Mamat, M. Z. Sahdan, N. Abdullah, and M. Rusop, "The effect of stabiliser's molarity to the growth of ZnO nanorods," Defect and Diffusion Forum, vol. 312-315, pp. 99-103, 2011.

[18] Y. Li, L. Xu, X. Li, X. Shen, and A. Wang, "Effect of aging time of $\mathrm{ZnO}$ sol on the structural and optical properties of $\mathrm{ZnO}$ thin films prepared by sol-gel method," Applied Surface Science, vol. 256, no. 14, pp. 4543-4547, 2010.

[19] M. J. Sailor, "Fundamentals of porous silicon preparation," in Porous Silicon in Practice: Preparation, Characterization and Application, pp. 1-42, Wiley-VCH, 1st edition, 2012.

[20] M. S. Kim, K. G. Yim, J.-Y. Leem et al., "Effects of annealing temperature on the structural and the optical properties of $\mathrm{ZnO}$ thin films grown on porous silicon by using plasma-assisted molecular beam epitaxy," Journal of the Korean Physical Society, vol. 59, no. 3, pp. 2343-2348, 2011.

[21] X. L. Huang, S. Y. Ma, L. G. Ma, H. Q. Bian, and C. Su, "Microstructure and optical properties of $\mathrm{ZnO}$ /porous silicon nanocomposite films," Physica E, vol. 44, no. 1, pp. 190-195, 2011.

[22] K. A. Eswar, A. Azlinda, F. S. Husairi, M. Rusop, and S. Abdullah, "Synthesis of $\mathrm{ZnO}$ thin film on porous silicon by spin coating in various low molarities precursor," Advanced Materials Research, vol. 701, pp. 167-171, 2013. 

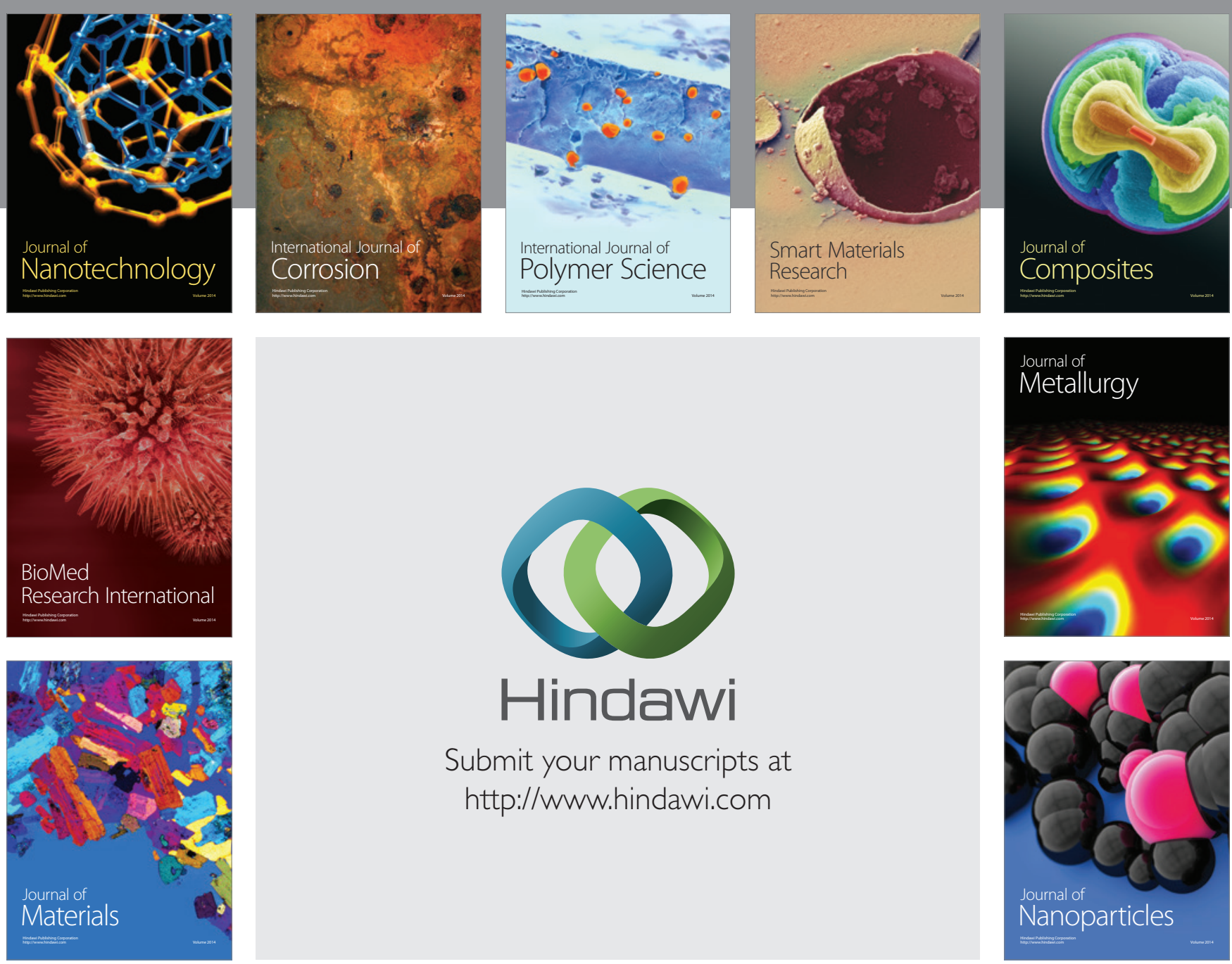

Submit your manuscripts at http://www.hindawi.com
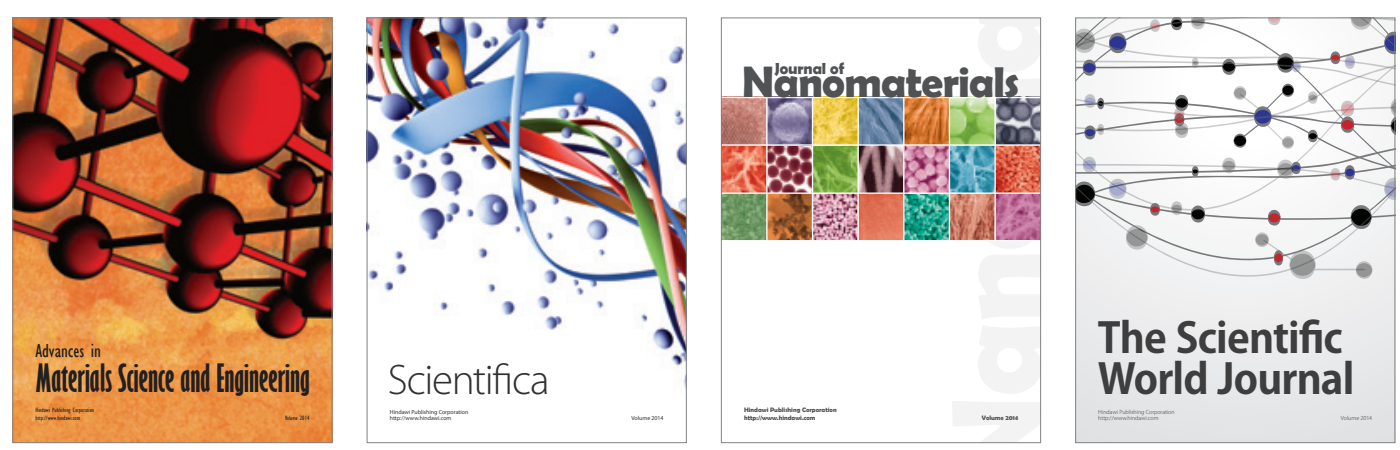

\section{The Scientific World Journal}
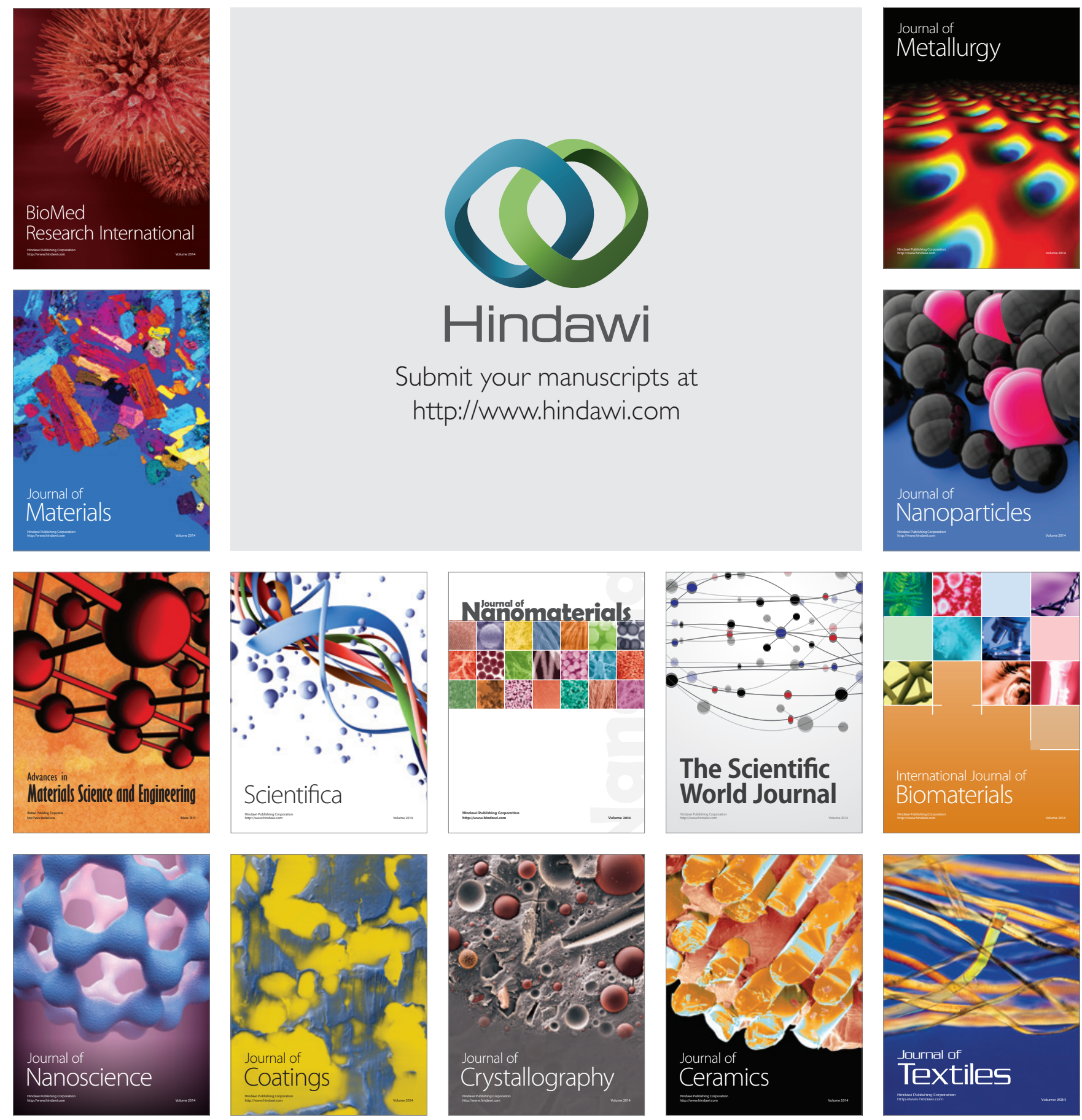